\title{
EL APARATO TEÓRICO EN LA ESTRUCTURA TRADICIONAL DEL SISTEMA DE PROPIEDAD INTELECTUAL*
}

\section{THE THEORETICAL APPARATUS OF INTELLECTUAL PROPERTY'S TRADITIONAL SYSTEM}

\author{
Juan Camilo Contreras-Jaramillo*** \\ Fecha de recepción: 15 de mayo de 2017 \\ Fecha de aceptación: 7 de junio de 2017 \\ Disponible en linea: 30 de noviembre de 2017
}

\section{Para citar este artículo/To cite this article}

Contreras-Jaramillo, Juan Camilo, El aparato teórico en la estructura tradicional del sistema de propiedad intelectual, 135 Vniversitas, 99-130 (2017). https://doi.org/10.11144/Javeriana.vj135.atet

doi:10.11144/Javeriana.vj135.atet

Artículo de reflexión elaborado en el marco del doctorado en ciencias jurídicas, Pontificia Universidad Javeriana.

** Profesor del departamento de derecho privado en la Facultad de Ciencias Jurídicas, Pontificia Universidad Javeriana. Contacto: juancontreras@javeriana.edu.co 


\section{RESUMEN}

Lo que conocemos hoy como el sistema de propiedad intelectual es un complejo entramado de explicaciones y reglas que tuvieron su origen en el contexto histórico y filosófico particular del siglo XVIII. De esta forma, el positivismo y el formalismo jurídicos amoldaron sus herramientas para poder comprender las creaciones e invenciones humanas como un tipo de derecho de propiedad. Como resultado de este proceso de adaptación, la estructura tradicional del sistema de propiedad intelectual obedece la misma estructura básica de la propiedad, cuya característica más relevante es la regla de propiedad respecto de este tipo de derechos subjetivos: exclusivos-excluyentes.

Palabras clave: Propiedad intelectual; positivismo; formalismo; reglas de propiedad 


\section{ABSTRACT}

The intellectual property system that we know today is a complex web of explanations and rules that originated in the historical and philosophical context of the XVIII century. Hence, legal positivism and formalism shaped their tools to fit the human creations and inventions as a kind of property right. Because of the adaptation process we find that the traditional structure of intellectual property corresponds to the same structure of property rights, where its most relevant characteristic is the property rule regarding these kind of rights: exclusive-excluding.

Keywords: Intellectual property; positivism; formalism; property rules

\section{SUMARIO}

INTRODUCCIÓN.- I. ORÍGENES DE LA ESTRUCTURA TRADICIONAL DEL SISTEMA DE PROPIEDAD INTELECTUAL.- $A$. La relación entre propiedad ordinaria y propiedad intelectual.- B. El espíritu naturalista y el método positivista en el sistema de propiedad intelectual.- II. CARACTERÍSTICAS DERIVADAS DE LA ESTRUCTURA TRADICIONAL DE LA PROPIEDAD INTELECTUAL.- $A$. La exégesis $y$ el formalismo en la propiedad sobre bienes incorporales.- B. El tipo de regla generado por la estructura tradicional del sistema de propiedad intelectual.- Conclusiones.- Bibliografía. 


\section{INTRODUCCIÓN}

Hoy, hacer referencia a los constantes ataques a la propiedad intelectual puede resultar un lugar común; desde iniciativas como el software libre o creative commons, pasando por la construcción de la paradoja de la piratería, las propuestas para declarar internet como un derecho fundamental, hasta las reivindicaciones de quienes promueven el libre acceso a medicamentos, en diferentes escenarios, la propiedad intelectual soporta críticas sobre su extensión, graduación, formalidades e, incluso, su misma existencia ${ }^{1}$.

Ante estos embates, la defensa de quienes buscan mantener el statu quo del sistema de propiedad intelectual usualmente está soportada por sofisticadas afirmaciones utilitaristas que reafirman la condición de incentivo que esta institución mantiene en nuestra sociedad ${ }^{2}$. Sin embargo, esta respuesta tan manida hoy parece carecer del peso suficiente para ser la única explicación, debido a que siempre es acompañada por una significativa reivindicación de la propiedad como un "tema jurídico"3.

En este artículo de reflexión se plantea que la tensión existente entre las explicaciones utilitaristas que defienden la propiedad intelectual como un incentivo para la creatividad y la innovación, de una parte, y las críticas al sistema de protección de bienes intangibles vigente, de otra, está relacionada con la estructura tradicional del sistema jurídico de propiedad intelectual, configurado durante los siglos XVIII y XIX y cuyas características devienen del contexto en que ese sistema fue gestado y desarrollado.

1 En este sentido, vemos cómo se ha justificado económicamente la piratería: Kal Raustiala \& Christopher Jon Sprigman, The Piracy Paradox Revisited, 61 Stanford Law Review, 5, 1201-1225 (2009). Disponible en: https://papers.ssrn.com/sol3/papers.cfm?abstract_id=1404247; cómo se ha privilegiado la garantía de los derechos de los consumidores al acceso a internet o a la información por encima de los titulares de derechos de propiedad intelectual: PETER K. Yu, Digital Copyright Enforcement Measures and Their Human Rights Threats, en Research Handbook on Human Rights and Intellectual Property, 455-477 (Christophe Geiger, ed., Edward Elgar Publishing, Cheltenham, Northampton, 2015). Disponible en: http://ssrn.com/abstract=2363945. Incluso, cómo se ha cuestionado la existencia misma de la protección de los intangibles. N. Stephan Kinsella, Against Intellectual Property, 15 Journal of Libertarian Studies, 2, 7-70 (2001). Disponible en: https://mises. org/library/against-intellectual-property-2

2 Mark A. Lemley, Ex Ante versus Ex Post Justifications for Intellectual Property (February 2, 2011), 71 University Chicago Law Review, 129-149 (2004); UC Berkeley Public Law Research Paper No. 144. Disponible en: https://papers.ssrn.com/sol3/papers.cfm?abstract_id=494424

3 David Álvarez-Amézquita, Óscar Eduardo Salazar \& Julio César Padilla-Herrera, Teoría de la propiedad intelectual. Fundamentos en la filosofía, el derecho y la economía, 15 Civilizar, 28, 61-76 (2015). Disponible en: http://revistas.usergioarboleda.edu.co/index.php/ccsh/article/view/280/237 
En este sentido, en el primer apartado del artículo, abordaremos la tarea de configurar esa estructura tradicional del sistema de propiedad intelectual; para luego, en el segundo capítulo, identificar cuál es el resultado de aquella estructura.

\title{
I. ORÍGENES DE LA ESTRUCTURA TRADICIONAL DEL SISTEMA DE PROPIEDAD INTELECTUAL
}

\begin{abstract}
Al referirnos a la estructura tradicional del sistema de propiedad intelectual, pretendemos ubicar un contexto temporal, filosófico y político que explique la creación de normas sobre propiedad intelectual y, más aún, la configuración de un sistema de normas con pretensiones globales. Ahora, para comenzar la tarea de estructurar el contexto dentro del cual surgió y se consolidó el sistema de propiedad intelectual, consideramos relevante desvincular el concepto de propiedad intelectual del de la historia de la inventiva humana; ambos — sin lugar a dudas - pueden tener puntos de encuentro pero no son equivalentes. Al identificar la historia de las invenciones o creaciones humanas como la misma historia de la propiedad intelectual, se estarían juzgando factores sociales y económicos dispares bajo un mismo criterio, lo cual genera conclusiones imposibles de verificar. En definitiva, resultaría incorrecto equiparar el significado social y económico de la máquina Antikythera ${ }^{4}$ de la antigua Grecia con el de una patente farmacéutica hoy ${ }^{5}$.

Al diferenciar estos dos relatos históricos, estamos rompiendo la narración continua y evolutiva que se le ha endilgado a la propiedad intelectual. Esta no es inherente al hombre mismo, no va de la mano con la evolución científica o creativa de la humanidad, no es una institución natural que ha crecido y mejorado en la medida en que nuestra sociedad se hace más sofisticada; la propiedad intelectual es un sistema jurídico construido y gestado socialmente en torno a factores históricos concretos, y cuyo resultado denominaremos
\end{abstract}

\footnotetext{
4 Michael T. Wright, Epicyclic Gearing and the Antikythera Mechanism, Part II, 29 Antiquarian Horology, 1, 51-63 (2005).

5 En este sentido, Hermenegildo Baylos-Corroza ha afirmado que hacer la historia de las creaciones técnicas e intelectuales "no es hacer la de la propiedad industrial o del derecho de autor". Hermenegildo Baylos-Corroza, Tratado de derecho industrial, 165 (Civitas, Madrid, 2009).
} 
la estructura tradicional o la visión ortodoxa de la propiedad intelectual ${ }^{6}$.

En suma, el propósito de este primer apartado es identificar el momento histórico y el contexto filosófico en el cual surge la propiedad intelectual como un sistema.

\section{A. La relación entre propiedad ordinaria y propiedad intelectual}

Desde la enmienda al Convenio de Estocolmo en $1979^{7}$, cuando la "propiedad intelectual" se designó como un término general dentro del cual caben las diferentes formas de protección de los bienes inmateriales, y desde una perspectiva terminológica (casi enciclopédica), parece no haber duda respecto a la identificación de la propiedad intelectual como un tipo de propiedad ${ }^{8}$. No obstante lo anterior, el estrecho vínculo entre la propiedad intelectual y su impacto en otras áreas de la vida social, como la economía,

6 Ver Kal Raustiala \& Christopher Jon Sprigman, The Piracy Paradox Revisited, 61 Stanford Law Review, 5, 1201-1225 (2009). O Adam Mossoff, Rethinking the Development of Patents: An Intellectual History, 1550-1800, 52 Hastings Law Journal, 1255-1322 (2001). Disponible en: https:// papers.ssrn.com/sol3/papers.cfm?abstract_id=863925. En estos artículos, la propiedad intelectual no es asociada con las invenciones o las creaciones, sino con el otorgamiento de monopolios reales.

7 Organización Mundial de Propiedad Intelectual, OMPI, Convenio que establece la Organización Mundial de la Propiedad Intelectual, Estocolmo, 14 de julio de 1967, enmendado el 28 de septiembre de 1979. Disponible en: http://www.wipo.int/treaties/es/convention/

8 Incluso, desde una concepción organizativa de las instituciones jurídicas, la propiedad intelectual y la propiedad ordinaria parecen coincidir. Como ejemplo se pueden tomar las sentencias de la Corte Constitucional colombiana que consagran la propiedad intelectual como tipo especial de propiedad, equiparada con formas de propiedad sobre bienes materiales. Colombia, Corte Constitucional, Sentencia C-006-93, 18 de enero de 1993, magistrado ponente Eduardo Cifuentes-Muñoz. Disponible en: http://www.corteconstitucional.gov.co/relatoria/1993/C-006-93.htm. Colombia, Corte Constitucional, Sentencia C-334-93, 12 de agosto de 1993, magistrado ponente Alejandro MartínezCaballero. Disponible en: http://www.corteconstitucional.gov.co/relatoria/1993/c-334-93.htm. Colombia, Corte Constitucional, Sentencia C-148-15, 7 de abril de 2015, magistrada ponente Gloria Stella Ortiz-Delgado. Disponible en: http://www.corteconstitucional.gov.co/relatoria/2015/c-148-15. $\mathrm{htm}$. Estas sentencias reconocen que los derechos de propiedad pueden recaer sobre bienes tangibles o intangibles, y que la propiedad intelectual comparte los elementos esenciales de la propiedad, como "el usus, el fructus y el abusus, con las limitaciones que establecen la Constitución y la ley". En otros ordenamientos: Estados Unidos, Corte Suprema de Justicia, Festo Corp. v. Shoketsu Kinzoku Kogyo Kabushiki Co., 535 US 722, 730 (May 28, 2002). Disponible en: https://supreme.justia.com/ cases/federal/us/535/722/. Estados Unidos, Corte Suprema de Justicia, Florida Prepaid Postsecondary Education Expense Board v. College Savings Bank et al., Certiorari to the United States Court of Appeals for the Federal Circuit, 527 US 627, 642 (June 23, 1999). Disponible en: https:// supreme.justia.com/cases/federal/us/527/627/case.html. Estas sentencias reconocen las patentes como propiedad. Unión Europea, Tribunal de Justicia, Gran Sala, Johan Deckmyn y Vrijheidsfonds VZW contra Helena Vandersteen y otros, Sentencia de 3 de septiembre de 2014, Asunto C-201/13. Disponible en: http://curia.europa.eu/juris/liste.jsf?language=es\&num=C-201/13 
la cultura y la tecnología, ha hecho que la relación con el derecho de propiedad se diluya 9 . Incluso, hasta el punto en que hay explicaciones del sistema actual de propiedad intelectual que omiten o minimizan el papel del derecho de propiedad en esta estructura, para otorgarle mayor relevancia al rol que, por ejemplo, puede jugar como incentivo de la economía o el fomento de la libre competencia $^{10}$; esta explicación se ha denominado justificación utilitarista de la propiedad intelectual ${ }^{11}$.

Sin embargo, consideramos que entender hoy la propiedad intelectual como una herramienta de mercado que busca la maximización de la utilidad o la libre competencia, no necesariamente riñe con la estructura tradicional del sistema de propiedad intelectual, el cual obedece a una relación jurídica de derecho real entre el titular de un derecho subjetivo y un bien inmaterial ${ }^{12}$, en la medida

9 Julie E. Cohen, What Kind of Property is Intellectual Property?, 52 Houston Law Review, 2, 691-707 (2014). Disponible en: http://www.houstonlawreview.org/wp-content/uploads/2015/01/8-Cohen.pdf

10 Mark A. Lemley, The Economics of Improvement in Intellectual Property Law (September 1, 2008), 75 Texas Law Review, 989-1084 (1997); Stanford Law and Economics Olin Working Paper No. 365. Disponible en: https://papers.ssrn.com/sol3/papers.cfm?abstract_id=1274199. William E. KovaciC \& Andreas P. Reinde, An Interdisciplinary Approach to Improving Competition Policy and Intellectual Property Policy, 28 Fordham International Law Journal, 4, 1062-1090 (2004). Disponible en: http://ir.lawnet.fordham.edu/ilj/vol28/iss4/7, http://ir.lawnet.fordham.edu/cgi/viewcontent.cgi? article $=1980 \&$ context $=$ ilj. Colombia, Consejo Nacional de Política Económica y Social, CONPES, Documento CONPES 3533, Bases de un plan de acción para la adecuación del sistema de propiedad intelectual a la competitividad y productividad nacional, 2008-2010 (14 de julio de 2008). Disponible en: http://www.disanejercito.mil.co/index.php?idcategoria=144363. Comisión Europea, Directrices sobre la aplicabilidad del artículo 101 del Tratado de Funcionamiento de la Unión Europea a los acuerdos de cooperación horizontal, 2011/C 11/01, Diario Oficial de la Unión Europea, 14 de enero de 2011. Disponible en: http://eur-lex.europa.eu/legal-content/ES/TXT/?uri=celex:52011XC0114(04). Estados Unidos, Federal Trade Commission, FTC, To Promote Innovation: The Proper Balance of Competition and Patent Law and Policy (October 2003). Disponible en: https://www.ftc.gov/ sites/default/files/documents/reports/promote-innovation-proper-balance-competition-andpatent-law-and-policy/innovationrpt.pdf

11 William W. Fisher, III, Geistiges Eigentum - ein ausufernder Rechtsbereich: Die Geschichte des Ideenschutzes in den Vereinigten Staaten, en Eigentum im internationalen Vergleich, 265-291 (Hannes Siegrist \& David Sugarman, hg., Vandenhoeck \& Ruprecht, Göttingen, Deutschland, 1999). William W. Fisher, III, The Growth of Intellectual Property: A History of the Ownership of Ideas in the United States en Eigentum im internationalen Vergleich, 265-291 (HANNES SIEGRIST \& DAVID Sugarman, eds., Vandenhoeck \& Ruprecht, Göttingen, Deutschland, 1999). Disponible en: https:// cyber.harvard.edu/people/tfisher/iphistory.pdf. Esta visión es puesta en duda por académicos como Robert P. Merges, Justifying Intellectual Property, 2-4, 33 (Harvard University Press, Cambridge, 2011). Adam Daniel Moore, A Lockean Theory of Intellectual Property, 21 The Hamline Law Review, 65-108 (1998). Disponible en: https://papers.ssrn.com/sol3/papers.cfm?abstract_id=1980882

12 Justin Hughes, Copyright and Incomplete Historiographies: of Piracy, Propertization, and Thomas Jefferson, 79 Southern California Law Review, $993-1084$ (2006). Disponible en: https://papers.ssrn. com/sol3/papers.cfm?abstract_id=934869. De hecho, John Locke, caracterizado como el germen de las teorías utilitarias, reconoció la relación entre la propiedad ordinaria y la propiedad intelectual; así lo afirma Robert P. Merges al leer An Essay Concerning Human Understanding, de Locke, en que este último reconoce su producción literaria como trabajo merecedor de la reivindicación propietaria. 
en que es posible identificar que el sistema de propiedad intelectual fue originalmente estructurado bajo las características filosóficas e históricas de la propiedad en el siglo XVIII y que hoy otros intereses $\mathrm{y}$ visiones confluyen a la hora de interpretar y aplicar la propiedad intelectual en la sociedad.

Justamente cuando la protección de las creaciones se equipara a la propiedad ordinaria, podemos hablar de un sistema de propiedad intelectual; antes de este momento - en el siglo XVIII-, la protección de las creaciones humanas o la inventiva humana no estaba estructurada como un derecho subjetivo sino como un privilegio otorgado por una autoridad estatal o monárquica ${ }^{13}$. En este sentido, podemos afirmar que el sistema de propiedad intelectual comienza con el reconocimiento de equivalencia entre este tipo de protección con la que otorgaba el derecho subjetivo de propiedad ordinaria. La incorporación del concepto de propiedad para la protección de intangibles en los diferentes sistemas jurídicos fue paulatina y coincidió con la omisión de consideraciones de política pública a la hora de otorgar los privilegios ${ }^{14}$ para comenzar a entender los bienes intangibles como bienes sujetos al poder de su creador.

Esta transición no ocurrió de forma pacífica, en la medida en que el sistema debió incorporar excepciones o nuevas interpretaciones a los conceptos tradicionales del derecho de propiedad; de esta forma, tuvieron lugar diferentes debates sobre los modos de adquirir la propiedad intelectual, la identificación de los bienes sobre los que podía recaer y la duración de la misma ${ }^{15}$. Este proceso terminó en la adecuación de los conceptos tradicionales de la propiedad para

Robert P. Merges, Justifying Intellectual Property, 33 (Harvard University Press, Cambridge, 2011).

13 Jean Cavalli, Génesis del Convenio de Berna para la Protección de las Obras Literarias y Artísticas del 9 de septiembre de 1886 (Ministerio del Interior y de Justicia, Dirección Nacional del Derecho de Autor, Telecom, Bogotá, 2006). Algunas excepciones se pueden identificar con los Estatutos para inventores de las repúblicas de Florencia (1421) y de Venecia (1474). BrucE W. BugBeE, Genesis of American Patent and Copyright Law (Public Affairs Press, Washington, 1967).

14 Herbert J. Hovenkamp, The Emergence of Classical American Patent Law, 58 Arizona Law Review, 263-306 (2016). Disponible en: https://papers.ssrn.com/sol3/papers.cfm?abstract_id=2625596, http:// scholarship.law.upenn.edu/cgi/viewcontent.cgi?article=2801\&context=faculty_scholarship

15 Estas construcciones de la teoría legal tienen dos grandes hitos en: (i) la sentencia Millar v. Taylor, de 1769, en el Reino Unido; y las publicaciones de Josef Kohler en Alemania. Brad Sherman \& Lionel Bently, The Making of Modern Intellectual Property Law: The British Experience, 17601910 (Cambridge University Press, Cambridge, 1999). Disponible en: http://s1.downloadmienphi. net/file/downloadfile4/206/1391108.pdf. Y Josef Kohler, Philosophy of Law (The Boston Book Company, Boston, 1914). Por ejemplo, se debatió sobre si la ocupación resultaba el modo idóneo para adquirir los derechos sobre obras del intelecto, o si la propiedad intelectual debería perdurar indefinidamente, como la propiedad ordinaria. 
acomodarse a una "nueva realidad", la de la propiedad inmaterial; llevando consigo toda la carga filosófica del momento histórico en el que se presentó esta adecuación.

\section{B. El espíritu naturalista y el método positivista en el sistema de propiedad intelectual}

La ubicación temporal del inicio del sistema tradicional de propiedad intelectual abarca los siglos XVIII y XIX; partiendo, generalmente, desde 1710 cuando se expidió el Estatuto de la Reina Ana ${ }^{16}$, para culminar en 1886 con la promulgación del Convenio de Berna ${ }^{17}$. Sin embargo, un simple recuento de los hitos en una línea de tiempo no ofrece el contexto amplio necesario para comprender quiénes iniciaron esta tarea, qué propósitos se fijaron y qué herramientas utilizaron. Para aproximarnos a estas cuestiones, resulta necesario revisar el contexto histórico y filosófico de ese momento, cuando se pueden rastrear evidencias en la sociedad, el arte y la literatura de una transición entre un pesimismo intelectual respecto de la realidad vigente ${ }^{18}$ y el descubrimiento de herramientas racionales que ayudaban a la construcción colectiva del ideal de sociedad ${ }^{19}$.

Este "pesimismo racional" - la humanidad sufría "la carencia de claridad y de armonía" 20 - fue una característica de la primera mitad del siglo XVIII y, a su vez, fue un claro antecedente del enciclopedismo y los proyectos codificadores del derecho que buscaban precisamente convertirse en instrumentos de claridad y armonía dentro de la sociedad. En esta misma línea, el positivismo jurídico buscó construir sistemas claros y armónicos y concentró gran parte

16 El título fue originalmente: An act for the encouragement of learning, by vesting the copies of printed books in the authors or purchasers of such copies, during the times therein mentioned. $\mathrm{Y}$ reconoció el derecho de un autor sobre su obra: "Whereas printers, booksellers, and other persons, have of late frequently taken the liberty of printing, reprinting, and publishing, or causing to be printed, reprinted, and published books, and other writings, without the consent of the authors or proprietors of such books and writings, to their very great detriment, and too often to the ruin of them and their families".

17 Unión para la Protección de los Derechos de los Autores sobre sus Obras Literarias y Artísticas, Convenio de Berna para la protección de las obras literarias y artísticas, 9 de septiembre de 1886. Disponible en: http://www.wipo.int/treaties/es/text.jsp?file_id=283698

18 Gabriel Josipovici, ¿Qué fue de la modernidad? (Turner, Colección Noema, Madrid, 2012).

19 Bernard Groethuysen, Filosofía de la Revolución Francesa, 27 (Fondo de Cultura Económica, FCE, México, 1989).

20 Bernard Groethuysen, Filosofía de la Revolución Francesa, 24 (Fondo de Cultura Económica, FCE, México, 1989). 
de su foco en los mecanismos de validación de la norma, para alejar su mirada de los análisis valorativos iusnaturalistas de la misma. Así, los Convenios de París y Berna pueden ser comprendidos como verdaderos códigos de propiedad intelectual, que obedecen al ideal de crear sistemas de normas claros y consecuentes en su expresión, también con una pretensión compiladora sobre todo el conocimiento posible de una materia concreta; son generales y construidos sobre principios, de forma que puedan abarcar cualquier situación fáctica.

Sin embargo, la anterior es una descripción de las herramientas utilizadas por quienes desarrollaron el sistema de propiedad intelectual y no explica el porqué de su elección. En este punto se hace palpable la relación entre el derecho positivo y el derecho natural racional que lo antecedió como corriente filosófica predominante.

Al ubicarnos temporalmente entre los siglos XVIII y XIX, estamos justo frente a la "puerta giratoria" entre el iusnaturalismo y el iuspositivismo ${ }^{21}$, cuando el primero daba paso al segundo como principal corriente doctrinal de la filosofía del derecho ${ }^{22}$. La relación entre estas dos corrientes ius filosóficas ha llevado a diferentes autores a calificar las teorías de los filósofos del derecho, entre finales del siglo XVIII y principios del XIX, como el resultado de una confusión insalvable entre naturalismo y positivismo ${ }^{23}$; de hecho, bajo la óptica más amplia de la corriente del derecho natural racionalista se suelen listar varios de los filósofos positivistas del derecho ${ }^{24}$.

21 Aunque las diferencias y similitudes entre las corrientes filosóficas del derecho natural (racionalista) y el derecho positivo exceden el objeto de este artículo, al acercarnos a esta última corriente doctrinal desde su perspectiva conceptual, o lo que Norberto Bobbio ha denominado "positivismo jurídico como enfoque", se puede comprender la idea de una "puerta giratoria" entre el naturalismo como una teoría previa y valorativa y el positivismo como una teoría posterior y descriptiva respecto del derecho. Norberto BobBio, El problema del positivismo jurídico (Distribuciones Fontamara, México, 2007). Ver también: Juan A. Pérez-Lledó \& Daniel González-Lagier, Apuntes sobre la filosofia del derecho de los siglos XIX y XX: de la Escuela de la Exégesis a Ronald Dworkin (2012). Disponible en: http://rua.ua.es/dspace/handle/10045/20557

22 Jerónimo Betegón-Carrillo, Marina Gascón-Abellán, Juan Ramón de Páramo \& Luis PrietoSANchís, Lecciones de teoría del derecho, 61 (McGraw-Hill, Madrid, 1997).

23 Julieta Marcone, Hobbes: entre el iusnaturalismo y el iuspositivismo, 1 Andamios, Revista de Investigación Social, 2, 123-148 (2005). Disponible en: http://www.redalyc.org/articulo.oa?id=62810206. Bernard Groethuysen, Filosofía de la Revolución Francesa (Fondo de Cultura Económica, FCE, México, 1989).

24 Como John Locke, Jean-Jacques Rousseau o Immanuel Kant. Jerónimo Betegón-CARRillo, Marina Gascón-Abellán, Juan Ramón de Páramo \& Luis Prieto-Sanchís, Lecciones de teoría del derecho, 52 (McGraw-Hill, Madrid, 1997). José María Rodríguez-Paniagua, El formalismo ético de Kant 
Si el derecho positivo describió el tipo de herramientas escogidas, el derecho natural explicó su contenido; para la concepción de aquel momento histórico, la razón creó los instrumentos de armonización en medio del caos existente, pero a su vez, mediante el derecho natural, se justificó su consagración. Y es que la razón universal tan manida en este período resultó ser un valor preexistente, previamente dado, que para los prerrevolucionarios franceses sería equivalente a las leyes de la naturaleza que constituirían derechos de todos los hombres en cualquier tiempo y circunstancia ${ }^{25}$. En los términos de la explicación que hace Michel Foucault sobre el análisis histórico de Friedrich Nietzsche sobre el conocimiento, las herramientas y el método del derecho positivo en el sistema de propiedad intelectual necesitaron de una explicación de "origen"26 para justificarse a sí mismas en ese momento histórico.

Precisamente, bajo la relación anteriormente descrita de las funciones valorativa naturalista y la descriptiva del positivismo, como las ha catalogado Norberto Bobbio ${ }^{27}$, se encuadra el inicio y desarrollo del sistema de propiedad intelectual; de una parte, la protección a las creaciones e invenciones humanas es valorada inicialmente como el "deber ser", y de la otra, posteriormente, la forma en que esa protección es estructurada se encuadra en un esquema lógico y formalista que tiene el objetivo de "disciplinar este tipo de creaciones" ${ }^{28}$. Es decir, visto el sistema de propiedad intelectual, como un producto final (luego del proceso de internacionalización llevado a cabo a finales del siglo XIX), el mismo está compuesto por un primer momento en que se buscan explicaciones de tipo naturalista o valorativa ${ }^{29}$, para luego encontrar una inclusión de

y el positivismo jurídico, 9 Anuario de Filosofia del Derecho, 35-50 (1962). Disponible en: https:// dialnet.unirioja.es/servlet/articulo?codigo $=2060145$

25 Bernard Groethuysen, Filosofía de la Revolución Francesa, 209 (Fondo de Cultura Económica, FCE, México, 1989).

26 Explicación originaria que resulta artificial según Friedrich Nietzsche. Michel Foucault, La verdady las formas jurídicas (Conferencias dictadas en la Pontifícia Universidade Católica do Rio de Janeiro, 1973). Disponible en: http://www.fmmeducacion.com.ar/Bibliotecadigital/Foucault_Laverdad.pdf

27 Julie E. Cohen, What Kind of Property is Intellectual Property?, 52 Houston Law Review, 2, 691-707 (2014).

28 José Luis Lacruz-Berdejo, Elementos de derecho civil, III, v. 2, 340 (Librería Bosch, Barcelona, 1980).

29 También se debe señalar la existencia de tesis positivistas puras que niegan por completo la prenormatividad de las creaciones o invenciones humanas; tales posiciones son minoritarias y surgen hasta el siglo XX. Ver Tullio Ascarelli, Teoría de la concurrencia y de los bienes inmateriales (Studia Albornotiana, 9, Bosch, Barcelona, 1970). 
esa primera explicación dentro del método positivista, el cual se limita a describir la operatividad formal del sistema.

Ese primer momento, que hemos denominado el "espíritu naturalista" de la propiedad intelectual, puede ser agrupado en dos grandes explicaciones originarias: (i) la teoría del merecimiento por el trabajo; y (ii) la garantía de libertades civiles por medio de la figura del propietario libre. La primera se asocia a los trabajos de John Locke y la segunda, a los filósofos de la Revolución Francesa; pero ambas están ligadas a las teorías generales sobre la propiedad reinantes durante ese momento histórico, cuando la libertad del hombre constituye el eje común.

En este sentido, la propiedad durante los siglos XVIII y XIX se convierte en una extensión del derecho natural de la libertad ${ }^{30}$ y constituye una explicación originaria. Para John Locke, esta caracterización se genera una vez se afirma que el hombre libre es propietario de sí mismo y por ende, el resultado del trabajo de su cuerpo, o las actividades transformadoras de sus manos, son $s u$ propiedad $^{31}$. En el mismo sentido, la propiedad como expresión de la libertad y mediante la cual se caracterizó al hombre como ciudadano, se reafirma desde 1789 con la aprobación de la Declaración de los Derechos del Hombre y del Ciudadano, e identificó la otra vertiente de la época que explicó la propiedad como una característica de todo hombre sin importar factores relativos como el tiempo o las condiciones particulares de cada individuo; esto es, el hombre libre y propietario, piedra angular de este movimiento ${ }^{32}$.

Estas dos explicaciones - que se toman prestadas de la propiedad ordinaria para hacerlas propias de este nuevo sistema ${ }^{33}$ - constituyen el primer momento del sistema de propiedad intelectual, el cual podemos calificar como el espíritu naturalista de la propiedad intelectual, por medio del cual se valoró indispensable otorgar a

30 Bernard Groethuysen, Filosofía de la Revolución Francesa, 214 (Fondo de Cultura Económica, FCE, México, 1989).

31 John Locke, Ensayo sobre el gobierno civil (Fondo de Cultura Económica, México, 1941). Ver también los comentarios de Robert Nozick sobre la teoría de la propiedad de Locke: RoBERT NozicK, Anarchy, State and Utopia, 171 (Blackwell Publishing, Malden, Oxford, 1999).

32 Jean-Jacques Rousseau, El contrato social (Panamericana, Bogotá, 1998).

33 Para Justin Hughes, en la medida en que se han adaptado a la propiedad intelectual, las teorías del trabajo y la personalidad agotan las justificaciones moralmente aceptables para la propiedad intelectual. Justin Hughes, The Philosophy of Intellectual Property, 77 The Georgetown Law Journal, 2, 287-366 (1988). Texto disponible en: https://pdfs.semanticscholar.org/3932/bdda601812eb$6212725 \mathrm{f} 38285 \mathrm{e} 72 \mathrm{dc} 8 \mathrm{fc} 70 \mathrm{~b} . \mathrm{pdf}$ 
un sujeto un tipo de protección respecto de las creaciones de su intelecto en la medida en que este sujeto es un hombre libre; este espíritu luego fue integrado ${ }^{34}$ a un método positivo formal que resulta también necesario desde la perspectiva histórica.

El método positivista que sobrevino no solo era expresión de la corriente ius filosófica imperante en ese momento, sino que además era una viva manifestación de la "puerta giratoria" entre iusnaturalismo y iuspositivismo que ya hemos mencionado anteriormente. La norma bajo este método queda sujeta a la decisión objetiva, circunstancial y verificable del legislador; sin embargo, el ciudadano sujeto a esa misma norma exige la construcción de un sistema jurídico claro y consecuente sobre la base de la igualdad. De esta forma, el método positivista, aunque en un segundo momento, resulta meramente descriptivo de la procedencia de las normas, y en un primer momento, es también expresión del deber ser; a partir de este entendimiento surgen los principios de igualdad ante la ley y de seguridad jurídica como garantes del hombre propietario libre, quien ejercerá su libertad a condición de obedecer únicamente la ley valedera que resulta igual a todos los ciudadanos ${ }^{35}$.

Incluso, quienes han identificado la tradición civilista como el único referente de las explicaciones naturalistas de la propiedad intelectual (también de la propiedad ordinaria), a la vez que califican el sistema anglosajón como el triunfo positivista del utilitarismo, reconocen que las normas de protección de la propiedad intelectual son producto de una razón universal y sus principios derivados ${ }^{36}$; esto hace patente el enlace histórico entre una explicación valorativa de tipo naturalista y su instrumentalización por medio de un método positivista.

34 Bien por la fuerza inherente del positivismo en ese momento histórico como la corriente predominante, o bien por la utilidad que esta corriente, independientemente de sus variables, prestaba al proyecto social del momento.

35 Bernard Groethuysen, Filosofía de la Revolución Francesa, 237 (Fondo de Cultura Económica, FCE, México, 1989).

36 Robert P. Merges, Justifying Intellectual Property, 95 (Harvard University Press, Cambridge, 2011). 


\section{CARACTERÍSTICAS DERIVADAS DE LA ESTRUCTURA TRADICIONAL DE LA PROPIEDAD INTELECTUAL}

\section{A. La exégesis y el formalismo en la propiedad sobre bienes incorporales}

Sumado a las explicaciones originarias, otro punto de conexión entre la propiedad ordinaria y la protección otorgada a las creaciones e invenciones humanas es el método utilizado en la aplicación e interpretación de los derechos reconocidos por el ordenamiento jurídico durante el siglo XIX, es decir, la interpretación exegética que compartieron la propiedad ordinaria y la propiedad intelectual durante este período. Con la expedición en Francia del Código Civil de Napoleón en 1804 se consolidó en el derecho civil la idea de un sistema jurídico definitivo y estable ${ }^{37}$; esta idea venía gestándose, como lo hemos afirmado anteriormente, desde 1789 con la promulgación de la Declaración de los Derechos del Hombre y del Ciudadano, y limitó durante todo el siglo XIX tanto la actividad legislativa que se vio paralizada, así como la actividad interpretativa de los operadores jurídicos, constreñidos a simplemente indagar la voluntad del legislador ${ }^{38}$ cuando la deducción lógico-formal no bastaba; tal método y estado de cosas es conocido como la escuela de la exégesis ${ }^{39}$.

En este escenario, al haberse calificado al derecho real de propiedad como un derecho absoluto en el texto de la ley, la interpretación de esta institución durante todo el siglo XIX no pudo más que remitirse a la voluntad del legislador, a los motivos que lo llevaron a utilizar esta precisa palabra; aunque hoy, desde la perspectiva que el paso del tiempo y el ajuste de las instituciones en la sociedad otorgan, podemos encontrar a quienes afirman que la propiedad nunca ha tenido la característica de absoluta. No obstante esto último, a

37 LÉon Duguit, Las transformaciones del derecho público y privado, 172 (Editorial Heliasta, Buenos Aires, 1975).

38 Henri Mazeaud, Léon Mazeaud \& Jean Mazeaud, Lecciones de derecho civil, 148 (Ediciones Jurídicas Europa-América, Buenos Aires, 1959).

39 Para ampliar el tema: Henri Mazeaud, Léon Mazeaud \& Jean Mazeaud, Lecciones de derecho civil, 157 (Ediciones Jurídicas Europa-América, Buenos Aires, 1959). Eugenio Llamas-Pombo, Orientaciones sobre el concepto y el método del derecho civil, 167 (Pontificia Universidad Javeriana, Bogotá, 2009). 
finales del siglo XVIII y comienzos del XIX, la propiedad fue concebida "primeramente en interés exclusivo de su beneficiario", como lo reconoce Louis Josserand ${ }^{40}$ al identificar el ejercicio absoluto de la propiedad ("el dogma del absolutismo") como la victoria de los derechos individuales (en especial de la burguesía) sobre los viejos gravámenes y la inaccesibilidad característica del período previo a la Revolución Francesa; de esta forma, la propiedad conformó en su momento, si bien no un derecho absoluto, sí el derecho con el más amplio ejercicio que solo encontró límites en el interés general y los derechos de terceros; e incluso tales límites sucumbían ante las facultades tan amplias otorgadas al titular, en la medida en que la libertad en el ejercicio del derecho de propiedad fue equiparada al mismo interés general que debía limitarlo ${ }^{41}$.

Aunque en la tradición anglosajona no se podría hablar en rigor de la existencia de un método exegético, propio de los sistemas codificados, el positivismo formalista ${ }^{42}$, consecuencia de los mismos ideales de coherencia y claridad civilistas, sí ha estado presente dentro del sistema del common law $w^{43}$, en que se ha reconocido que durante el siglo XIX se estableció plenamente un sistema jurídico de tipo deductivo, que incluso se ha llegado a catalogar como la tradición de la respuesta única que adhería de forma estéril al precedente o la legislación ${ }^{44}$. Basta referenciar una de las frases célebres de Christopher Langdell al referirse a su método de estudio de casos: "el derecho es una ciencia, y... todos los materiales disponibles de dicha ciencia se encuentran en los libros impresos" $" 45$, para de esta forma evidenciar la idea de un sistema armónico, claro y del cual se podía deducir "científicamente" el verdadero significado de la norma sin acudir a sus propósitos ${ }^{46}$.

40 Louis Josserand, Derecho civil, 79 (Bosch, Buenos Aires, 1950).

41 José Luis Lacruz-Berdejo, Elementos de derecho civil, III, v. 1, 171 (Librería Bosch, Barcelona, 1980).

42 El formalismo jurídico entendido como una categoría más amplia del positivismo en que se pueden incluir el formalismo legal (exégesis), el formalismo jurisprudencial alemán y la jurisprudencia analítica inglesa. Juan A. Pérez-Lledó \& Daniel González-Lagier, Apuntes sobre la filosofía del derecho de los siglos XIX y XX: de la Escuela de la Exégesis a Ronald Dworkin (2012).

43 David Dyzenhaus, The Genealogy of Legal Positivism, 24 Oxford Journal of Legal Studies, 1, 39-67 (2004).

44 Karl N. Llewellyn, The Common Law Tradition: Deciding Appeals, 64-157 (Little, Brown \& Company, Boston, 1960).

45 Patrick Kelley citando a Christopher Langdell. Patrick J. Kelley, Holmes, Langdell and Formalism, 15 Ratio Juris, 1, 26-51, 35 (2002).

46 Neil J. Smelser \& Paul B. Baltes, eds., International Encyclopedia of the Social \& Behavioral 
No es de extrañar que al identificar el mismo método positivo en el sistema anglosajón, cercano a la exégesis, surja, al igual que en el sistema del derecho civil, una relación muy cercana entre iuspositivismo y iusnaturalismo; todo tipo de formalismo legal, en cuanto se limitará a describir la operatividad formal de la norma, debe profesar siquiera la posibilidad de una "racionalidad moral inmanente" 47 , es decir, una explicación valorativa o naturalista. En este contexto también está la ya referida puerta giratoria entre iusnaturalismo y positivismo, en la medida en que encuentra la justificación valorativa de la propiedad en la teoría naturalista del trabajo de John Locke ${ }^{48}$ de la mano con explicaciones que validan el derecho desde la aplicación de principios doctrinales, como en el caso de Jeremy Bentham, John Austin o John Stuart Mill ${ }^{49}$; en este sentido, autores como Dan Priel han identificado grandes coincidencias entre las visiones positivistas y naturalistas en el derecho anglosajón ${ }^{50}$.

Todo lo anterior cobra sentido para nuestro argumento cuando afirmamos que tanto en la tradición jurídica civilista, como en la tradición del common law, el sistema de propiedad intelectual se construyó durante los siglos XVIII y XIX sobre las mismas bases de la propiedad ordinaria y toma prestados dos elementos: (i) la explicación valorativa de carácter natural; y (ii) el método positivista más cercano a la exégesis. Sin importar la decisión superficial de adoptar una categoría jurídica idéntica o crear un régimen especial, la propiedad intelectual desde el siglo XVIII, después de abandonar su estructura de privilegios asignados, fue regulada como un derecho de propiedad puro y simple ${ }^{51}$.

De esta manera, podemos afirmar que la construcción de la estructura tradicional del sistema de propiedad intelectual, o lo que

Sciences, 8364 (Elsevier, Stanford, California, 2001).

47 ERnest J. WeInRIB, Legal Formalism: On the Immanent Rationality of Law, 97 The Yale Law Journal, 6, 949-1016, 953 (1988).

48 John Locke, Ensayo sobre el gobierno civil (Fondo de Cultura Económica, México, 1941).

49 John Stuart Mill, Principles of Political Economy (William J. Ashley, ed., Longmans, Green and Co., London, 1965).

50 Dan Priel, Towards Classical Legal Positivism, Osgoode CLPE Research Paper No. 20 (2011). Disponible en: https://papers.ssrn.com/sol3/papers.cfm?abstract_id=1886517. Ver también, JuLIETA Marcone, Hobbes: entre el iusnaturalismo y el iuspositivismo, 1 Andamios, Revista de Investigación Social, 2, 123-148 (2005).

51 Herbert J. Hovenkamp, The Emergence of Classical American Patent Law, 58 Arizona Law Review, 263-306 (2016). 
Kal Raustiala y Christopher Jon Sprigman ${ }^{52}$ han denominado la visión ortodoxa de la propiedad intelectual, hizo propia esa puerta giratoria de la propiedad ordinaria durante los siglos XVIII y XIX, asumiendo, además las explicaciones originarias de las teorías del merecimiento por el trabajo y la de la garantía de libertades civiles con la figura del propietario libre, sino que además incorporó muy hábilmente el método positivista exegético imperante en ese momento. Esta combinación superó fronteras físicas y jurídicas en la medida en que la propiedad intelectual, como sistema, se globalizó en un momento histórico en el que Europa, en especial Alemania y Francia, constituía el centro global y los demás países espacios de recepción normativa ${ }^{53}$; como lo ha expresado Margrit Seckelmann: "Las bases del modelo occidental de propiedad intelectual fue influenciado [en sus inicios] más por el Iluminismo que por el Protestantismo" 54 . En el caso de la propiedad intelectual, su sistema obtuvo una mayor penetración gracias al proceso amplio de internacionalización que comenzó con los Convenios de París y Berna a finales del siglo XIX.

\section{B. El tipo de regla generado por la estructura tradicional del sistema de propiedad intelectual}

La estructura tradicional de la propiedad intelectual, resultado de los factores anteriormente descritos, finalmente se caracteriza por la conformación de un derecho de propiedad, es decir, un derecho subjetivo que opera bajo una "regla de propiedad". Este tipo de regla es la conclusión del proceso de adecuación que hemos descrito hasta ahora, y lo identificamos como una característica rastreable hasta nuestros días.

Más allá de las diferentes explicaciones o intereses que sustentaron la consolidación o la elección de los derechos de propiedad

52 Kal Raustiala \& Christopher Jon Sprigman, The Piracy Paradox Revisited, 61 Stanford Law Review, 5, 1201-1225 (2009).

53 Duncan Kennedy, Tres globalizaciones del derecho y del pensamiento jurídico, 1850-2000 (JoRgE GonzÁlez-Jácome, trad., Universidad Externado de Colombia, Bogotá, 2015). Jorge GonZÁleZJÁcOME, Los debates del pensamiento jurídico colombiano entre 1886 y 1920 (Pontificia Universidad Javeriana, Bogotá, 2011).

54 Margrit Seckelmann, From the Paris Convention (1883) to TRIPS Agreement (1994): the History of the International Patent Agreements as a History of Propertisation?, 14 Jahrbuch der Juristischen Zeitgeschichte, 1, 46-63, 57 (2013). 
en la sociedad, el uso de la "regla de propiedad" constituye una característica instrumentalizadora de esos diversos intereses filosóficos, políticos o económicos que han permeado las reivindicaciones propietarias ${ }^{55}$. En este apartado, procederemos a caracterizar la "regla de propiedad" como ese elemento más o menos estable en el tiempo y que ha caracterizado la estructura del derecho de propiedad en general, y la estructura tradicional de la propiedad intelectual; es decir, nos referimos a los elementos que conforman el núcleo esencial del derecho de propiedad ${ }^{56}$, más allá de las diferentes justificaciones o acepciones que la propiedad pueda tener.

En primera instancia, al realizar la abstracción de las características del derecho subjetivo que tiene el titular de un derecho de propiedad $^{57}$, es posible acercarse al tipo de acciones que este sujeto puede realizar respecto del objeto de su derecho; es decir, lo que el propietario puede hacer con el bien objeto de su propiedad. Esta característica "positiva" del derecho de propiedad puede ser entendida en palabras de Jeremy Waldron como las "reglas de derecho que determinan qué tipo de acciones se pueden realizar respecto de qué tipo de bienes" 58 .

Sin embargo, como lo han descrito Armen A. Alchian y Harold Demsetz, esta característica "positiva" del derecho de propiedad no derivará en todos los casos en una "regla de propiedad". Esto

55 Sobre los diferentes intereses que explican la propiedad, sus distintas acepciones y la naturaleza cambiante de las mismas: StEFAnO RoDOtȦ, El terrible derecho. Estudios sobre la propiedad privada (Civitas, Madrid, 1986).

56 En el sistema de derecho civil, estos poderes son descritos como el uso, el goce y la disposición respecto del bien objeto del derecho de propiedad. Arturo Alessandri, Manuel Somarriva \& Antonio Vodanovic, Derecho civil. Tratado de los derechos reales. Bienes. Tomo I (Editorial Jurídica de Chile, Santiago, 2014). Y las sentencias de la Corte Constitucional: Colombia, Corte Constitucional, Sentencia C-006-93, 18 de enero de 1993, magistrado ponente Eduardo Cifuentes-Muñoz. Colombia, Corte Constitucional, Sentencia C-595-99, 18 de agosto de 1999, magistrado ponente Carlos Gaviria-Díaz. Disponible en: http://www.corteconstitucional.gov.co/relatoria/1999/c-595-99. $\mathrm{htm}$. Este mismo núcleo esencial de la propiedad puede no coincidir con la forma en que el sistema de common law ha descrito el poder de la propiedad respecto del objeto; al efecto, ver: THomas C. Grey, The Disintegration of Property, en Property, Nomos XXII, 69-85 (J. Roland Pennock \& John W. Chapman, eds., New York University Press, New York, 1980). Disponible en: https://www.jstor. org/stable/24219422?seq=1\#page_scan_tab_contents. O JesSE DukEMINIER \& JAMES Krier, Property (Little, Brown and Company, Boston, 1993). Sin embargo, como se verá más adelante, ambos sistemas tienen un denominador común tras el ejercicio del poder asignado al titular de la propiedad.

57 O múltiples derechos, como se entiende en la doctrina mayoritaria de tradición anglosajona; el conjunto se denomina bundle of rights. Thomas C. Grey, The Disintegration of Property, en Property, Nomos XXII, 69-85 (J. Roland Pennock \& John W. Chapman, eds., New York University Press, New York, 1980).

58 Jeremy Waldron, The Right to Private Property, 31 (Clarendon Press, Oxford, 1988). O Robert NozicK, Anarchy, State and Utopia, 171 (Blackwell Publishing, Malden, Oxford, 1999). 
debido a que es posible encontrar casos en los que el derecho a usar una cosa existe, no obstante se trata de un "derecho común" (o de uso comunal), distinto a la propiedad privada. Para ejemplificar la inconsistencia del factor positivo, los autores usan el ejemplo del derecho a usar la plaza de una ciudad o una autopista en donde los beneficiarios ostentan el derecho a usar sin ostentar simultáneamente un derecho de propiedad ${ }^{59}$.

Armen A. Alchian y Harold Demsetz consideran que la característica de las reglas de propiedad presente en todo derecho de propiedad es la posibilidad de excluir que ostenta el propietario; a esto le han denominado el "derecho del propietario ausente" para excluir ${ }^{60}$.

En este mismo sentido, Henry E. Smith reconoce al derecho a excluir como pieza fundamental de toda propiedad ${ }^{61}$; partiendo del reconocimiento del derecho de propiedad en la tradición anglosajona, la explicación positiva puede generar confusiones entre las relaciones jurídicas debido al concepto de los bundle of rights (o conjunto de derechos) ${ }^{62}$. James E. Penner, al criticar la teoría de los bundle of rights, también reconoce la exclusión (denominada como deber de no interferencia) como el elemento más evidente y que menos dificultades presenta entre los derechos in rem re $^{63}$.

En el common law, la exclusión es un elemento de las reglas de propiedad, incluso entre quienes reafirman las teorías propietarias derivadas del concepto del bundle of rights; por ejemplo, al describir los múltiples derechos de propiedad, Richard A. Posner enfatiza cómo cada uno de esos derechos que conforman la propiedad se

59 Armen A. Alchian \& Harold Demsetz, The Property Right Paradigm, 33 The Journal of Economic History, 1, The Tasks of Economic History, 16-27 (March 1973). Disponible en: http://www.fd.unl. pt/docentes_docs/ma/LTF_MA_24397.pdf

60 Armen A. Alchian \& Harold Demsetz, The Property Right Paradigm, 33 The Journal of Economic History, 1, The Tasks of Economic History, 16-27, 19 (March 1973).

61 Este reconocimiento recoge una amplia doctrina en el mismo sentido. Henry E. Smith, Exclusion and Property Rules in the Law of Nuisance, 90 Virginia Law Review, 4, 965-1049, 972 (2004). Disponible en: http://digitalcommons.law.yale.edu/cgi/viewcontent.cgi?article $=4054 \&$ context $=$ fss_papers

62 Henry E. Smith, Property and Property Rules, 79 New York University Law Review, 1719-1798, 1792 (2004). Disponible en: http://digitalcommons.law.yale.edu/cgi/viewcontent.cgi?article=4053\&context=fss_papers. Bruce ACKerman, Private Property and the Constitution, 27 (Yale University Press, New Haven, London, 1977).

63 James E. Penner, The "Bundle of Rights" Picture of Property, 43 UCLA Law Review, 3, 711-820 (1996). Larissa M. Katz, Exclusion and Exclusivity in Property Law (Legal Studies Research Paper Series No. 08-02, April 1, 2008). Disponible en: https://papers.ssrn.com/sol3/papers.cfm?abstract_id=1126674 
ejercerá de forma exclusiva y excluyendo a otros de su aprovechamiento ${ }^{64}$.

El poder de excluir a terceros es entendido por la doctrina como el ejercicio del dominio mismo y el motivo fundante del derecho de propiedad; en este sentido, la teoría de la Tragedia de los Comunes elabora una completa justificación del derecho de propiedad como herramienta para excluir a otros del uso de un bien, con el objetivo de evitar el sobreuso de los mismos bienes ${ }^{65}$.

La exclusión de terceros como denominador común en las reglas de propiedad no resulta extraña al sistema de derecho civil y no debería ser entendida de forma separada de los denominados poderes del propietario (uso, goce y disposición). De hecho, la exclusión no solamente es entendida por algunos como uno de los atributos de la propiedad ${ }^{66}$, es decir, aplicable a toda la concepción del derecho subjetivo, sino que hay también quienes identifican la exclusión como la explicación misma de la propiedad. En este sentido, Paolo Grossi afirma que la característica de exclusividad (entendida en sentido positivo: de aprovechamiento propio; en sentido negativo, de excluir a terceros) es un mínimo necesario para que haya propiedad en cualquier tiempo ${ }^{67}$.

Como lo afirma Héctor Santaella-Quintero, al analizar el derecho de propiedad bajo la óptica del derecho constitucional colombiano, entender la propiedad constitucional supone definir este

64 Richard A. Posner, El análisis económico del derecho, 36 ss. (Fondo de Cultura Económica, México, 1998). Ronald Coase, The Firm, the Market, and the Law (The University of Chicago Press, Chicago, London, 1990). Thomas W. Merrill \& Henry E. Smith, Making Coasean Property More Coasean (February 9, 2011), 54 Journal of Law and Economics, 4, S77-S104 (2011); Harvard Law and Economics Discussion Paper No. 688; Columbia Public Law Research Paper No. 11-262. Disponible en: https://papers.ssrn.com/sol3/papers.cfm?abstract_id=1758846. Resulta importante aclarar que para quienes defienden la teoría del bundle of rights, la propiedad no es entendida como unidad; es, por el contrario, un concepto flexible, incluso puede llegar a ser indeterminado y únicamente se puede alcanzar claridad sobre cada uno de los derechos que la conforman. En el sistema anglosajón hay quienes buscan dejar atrás la teoría del bundle of rights y pretenden retomar otras explicaciones. Adam Mossoff, What is Property? Putting the Pieces Back Together, 45 Arizona Law Review, 371443 (2003). Disponible en: https://papers.ssrn.com/sol3/papers.cfm?abstract_id=438780

65 Julie E. Cohen, What Kind of Property is Intellectual Property?, 52 Houston Law Review, 2, 691707, 700 (2014). Sobre la tragedia de los comunes: Elinor Ostrom, Governing the Commons. The Evolution of Institutions for Collective Action (Cambridge University Press, Cambridge, 2015).

66 Luis Díez-Picazo \& Antonio Gullón-Ballesteros, Sistema de derecho civil, volumen III, Tomo 1, 141 ss. (Tecnos, Madrid, 2012).

67 Paolo Grossi, La propiedad y las propiedades en el gabinete del historiador, 107 ss. (Civitas, Madrid, 2016). Afirma que el ius ceteros excludendi "es inherente a su naturaleza, concernir a su intrínseca constitución". 
derecho como "un ámbito de aprovechamiento privado exclusivo y excluyente (...)"

Como hemos visto, entre la aproximación positiva (las acciones que el titular puede realizar) y la negativa (las acciones que el titular puede evitar que otros realicen) de las características de la regla de propiedad, encontramos el binomio "exclusivo-excluyente". En este sentido, entendemos como "regla de propiedad" el binomio exclusivo-excluyente o, en otras palabras, este binomio es la estructura lógica básica que caracteriza los derechos de propiedad.

Esta "regla de propiedad" no pretende justificar por sí sola la existencia o la extensión de la propiedad, tampoco determina los mecanismos de asignación de la propiedad en una sociedad. La "regla de propiedad" propuesta sirve para reconocer en un derecho su cercanía o no al derecho de propiedad; en la medida en que un derecho incluya un mayor grado de "exclusividad-exclusión" se acercará más a una regla de propiedad; $y$, por el contrario, cuando un derecho se aleja del binomio también lo hace de la propiedad ${ }^{69}$.

Esta "regla de propiedad" lleva implícito un poder de señorío, un poder, en consecuencia, individualista; bajo la regla de propiedad, se otorga decididamente mayor peso al interés particular de quien ostenta ese poder. No obstante, lo anterior no puede interpretarse necesariamente como la descripción de un derecho absoluto a favor del titular, consecuencia de la aplicación de la regla de propiedad.

El estado actual de la discusión sobre los efectos del sistema de protección de la propiedad intelectual, en algunos casos, ha llevado a que los propósitos y efectos del mismo sistema sean equiparados a los mecanismos de protección utilizados. En este apartado, pretendemos marcar la diferencia entre las causas y los efectos de los derechos de propiedad intelectual (en adelante, DPI) respecto de la estructura utilizada para proteger a la propiedad intelectual.

Como la doctrina mayoritaria lo ha reconocido, el sistema de propiedad intelectual se sirve de "reglas de propiedad", indepen-

68 Héctor Santaella-Quintero, Notas sobre el concepto y la garantía de la propiedad privada en la Constitución colombiana, 21 Revista de Derecho Privado, 233-253 (julio-diciembre de 2011). Disponible en: http://revistas.uexternado.edu.co/index.php/derpri/article/view/2989/2633. Para ahondar en la exclusión de terceros como elemento identificador de la regla de propiedad, en el derecho civil: José GonzÁlez-García, La facultad de exclusión del propietario (Universidad de Granada, Granada, 1986).

69 Y se estará acercando a otro tipo de reglas o relaciones jurídicas, como pueden ser las personales, las de responsabilidad o las de derechos personalísimos. 
dientemente de los propósitos fijados o los efectos obtenidos mediante dichas reglas. Aunque el sistema de propiedad intelectual y el derecho de propiedad ordinaria han tenido una relación cercana que ha llevado, incluso, a que el primero utilice elementos del primero para justificarse o para establecer categorías jurídicas, acá nos concentran las "reglas de propiedad", es decir, en el uso del binomio "exclusivo-excluyente" para moldear el sistema de protección de los derechos de propiedad intelectual.

Como lo hemos señalado anteriormente, la evolución del mismo sistema de propiedad intelectual se dio de manera paulatina y su cercanía con el derecho de propiedad se puede identificar con mayor claridad en la medida en que la protección de intangibles abandonó las consideraciones de política pública o aprovechamiento ${ }^{70}$, propias de los privilegios otorgados por medio de monopolios, para acercarse a las "reglas de propiedad" que enfatizaron la condición "exclusiva y excluyente"

Como hemos dicho, independientemente de las justificaciones ${ }^{72}$ que llevan a comprobar la implementación de "reglas de propiedad" para la protección de intangibles ${ }^{73}$, es posible identificar la invariable

70 Mario Biagioli, Patent Specification and Political Representation: How Patents Became Rights, en Making and Unmaking Intellectual Property: Creative Production in Legal and Cultural Perspective, 25-40 (Mario Biagioli, Peter Jaszi \& Martha Woodmansee, eds., University of Chicago Press, Chicago, 2011). Reconoce cómo en las primeras etapas del sistema de protección de patentes, como en la República de Venecia (1594) o en Estados Unidos antes del US Patent Act de 1790, las patentes eran consideradas "regalos" del soberano que tenían un propósito netamente utilitario. HERBERT J. Hovenkamp, The Emergence of Classical American Patent Law, 58 Arizona Law Review, 263-306 (2016). Habla del primer sistema de patentes de Estados Unidos como un sistema de privilegios que premiaban la utilidad pública de los inventos. Para el derecho de autor: CATERINA SGANGA, EU Copyright Law between Property and Fundamental Rights: A Proposal to Connect the Dots, en Balancing Copyright Law in the Digital Age: Comparative Perspectives, 1-26 (RoBerto CAso \& Federica Giovanella, eds., Springer, Berlin, Heidelberg, 2015).

71 Aunque autores como Adam Mossoff defienden la existencia de "reglas de propiedad" en los DPI, incluso durante todo el siglo XVIII, debido a la preeminencia que el derecho natural (teoría del trabajo y el contrato social) tenía sobre la protección de intangibles en aquel momento; y niegan la identificación histórica de los primeros sistemas de PI como privilegios limitados. AdAm Mossoff, Who Cares What Thomas Jefferson Thought About Patents? Reevaluating the Patent "Privilege" in Historical Context, 92 Cornell Law Review, 5, 953-1012 (2007); MSU Legal Studies Research Paper No. 03-21. Disponible en: http://scholarship.law.cornell.edu/cgi/viewcontent.cgi?article=3067\&context $=$ clr

72 Aunque algunos autores han reconocido que la justificación misma de la propiedad intelectual es la de otorgar control al titular de derechos. William W. Fisher, III, When Should We Permit Differential Pricing of Information?, 55 UCLA Law Review, 1, 1-38, 14 (2007). Disponible en: https:// www.uclalawreview.org/pdf/55-1-1.pdf

73 Mark A. Lemley, Ex Ante versus Ex Post Justifications for Intellectual Property (February 2, 2011), 71 University Chicago Law Review, 129-149 (2004); UC Berkeley Public Law Research Paper No. 144. Describe los dos tipos de justificaciones existentes en la propiedad intelectual para adoptar 
relación jurídica de un derecho "exclusivo-excluyente" a través del tiempo, mediante el cual se crea una barrera jurídica para asegurar el control ${ }^{74}$ del titular del derecho respecto de los usos (en sentido amplio) que se le puedan dar al objeto protegido $^{75}$.

derechos exclusivos que otorgan un control al titular.

74 Control basado sobre la ficción legal de crear escasez allí donde no existe naturalmente. WiLLiam M. LANDes \& Richard A. Posner, The Economic Structure of Intellectual Property Law (Harvard University Press, Cambridge, 2003).

75 Charles William Maughan, Property and Intellectual Property: Foundations in Law and Economics, 22 Prometheus, Critical Studies in Innovation, 4, 379-391 (December, 2004). 


\section{CONCLUSIONES}

A partir de la identificación del período histórico en el que se gestó el sistema tradicional de propiedad intelectual, hemos podido explicar su aparato teórico y sus características, que derivan de las prácticas sociales que tomaron lugar entre los siglos XVIII y XIX. En este sentido, la estrecha relación entre iusnaturalismo y iuspositivismo que caracterizó el momento histórico analizado, llevó a que el sistema mismo se integrara en dos tiempos: la explicación valorativa y originaria que obedece al derecho natural, y la descripción instrumental del método aplicado que obedece al derecho positivo. La acción concomitante de estos dos tiempos, sumada a la necesidad temporal de construir seguridad en medio de una sensación de caos, llevó a que el método se convirtiera en sí mismo en una justificación del sistema de propiedad intelectual; en este sentido, todas las discusiones sobre la eficiencia, la interpretación o la graduación de los derechos de propiedad intelectual, aunque son puestas sobre la mesa como discusiones sobre las explicaciones o las justificaciones del propio sistema, en realidad hacen parte del debate sobre el método del sistema de propiedad intelectual, en la medida en que se consolidó una tendencia a equiparar al método como una explicación justificativa del mismo sistema de propiedad intelectual.

Más allá de las explicaciones y justificaciones de la propiedad intelectual, el reconocimiento de esta como un derecho de propiedad que incorpora una "regla de propiedad" no solo se evidenció durante todo el período de consolidación del sistema tradicional de propiedad intelectual, sino que hoy pervive en la doctrina ${ }^{76}$, en la jurisprudencia ${ }^{77}$, e incluso, el objeto de los DPI (los bienes in-

76 Entre otros, Adam Mossoff, Exclusion and Exclusive Use in Patent Law, 22 Harvard Journal of Law \& Technology, 2, 321-379 (2009). Disponible en: http://jolt.law.harvard.edu/articles/pdf/v22/22HarvJLTech321.pdf. Julie E. Cohen, What Kind of Property is Intellectual Property?, 52 Houston Law Review, 2, 691-707, 691 (2014). HÉctor SANTAELlA-Quintero, Notas sobre el concepto y la garantía de la propiedad privada en la Constitución colombiana, 21 Revista de Derecho Privado, 233-253 (julio-diciembre de 2011). Timothy J. Brennan, Copyright, Property, and the Right to Deny, 68 Chicago-Kent Law Review, 2, 675-714 (1992). Disponible en: http://scholarship.kentlaw.iit.edu/cgi/ viewcontent.cgi?article $=2890 \&$ context $=$ cklawreview

77 En Colombia, las sentencias C-006-03, C-334-93 y C-148-15 de la Corte Constitucional reconocen que los derechos de propiedad pueden recaer sobre bienes tangibles o intangibles, y que la propiedad intelectual comparte los elementos esenciales de la propiedad, como "el usus, el fructus y el abusus, con las limitaciones que establecen la Constitución y la ley”. En Estados Unidos, las sentencias 
tangibles) ha sido equiparado a los bienes objeto de la propiedad ordinaria a efectos de la ley ${ }^{78}$. La identificación de la propiedad intelectual con las "reglas de propiedad" se termina de consolidar con la "cosificación" de los DPI, evidente en su consideración como objeto de garantía (mobiliaria) y resultado de su valoración patrimonial; esto resulta indispensable para poder predicar la "exclusividad-exclusión" propia de las "reglas de propiedad"79 y consecuencia de la evolución que sufrió esta institución desde el siglo XVIII hasta nuestros días.

Festo Corp. v. Shoketsu Kinzoku Kogyo Kabushiki Co., 535 US 722, 730 (May 28, 2002) y Florida Prepaid Postsecondary Education Expense Boardv. College Savings Bank et al., Certiorari to the United States Court of Appeals for the Federal Circuit, 527 US 627, 642 (June 23, 1999), de la Corte Suprema de Justicia, reconocen las patentes como propiedad. Unión Europea, Tribunal de Justicia, Gran Sala, Johan Deckmyn y Vrijheidsfonds VZW contra Helena Vandersteen y otros, Sentencia de 3 de septiembre de 2014, Asunto C-201/13.

78 España, Ley sobre Hipoteca Mobiliaria y Prenda sin Desplazamiento de la Posesión en España, de 16 de diciembre de 1954, 352 Boletín Oficial del Estado, BOE, 18 de diciembre de 1954. Disponible en: https:/www.boe.es/buscar/act.php?id=BOE-A-1954-15448. Colombia, Ley 1676 de 2013, por la cual se promueve el acceso al crédito y se dictan normas sobre garantías mobiliarias, 48.888 Diario Oficial, 20 de agosto de 2013. Disponible en: http://www.secretariasenado.gov.co/senado/basedoc/ ley_1676_2013.html

79 James E. Penner, The “Bundle of Rights" Picture of Property, 43 UCLA Law Review, 3, 711-820 (1996). 


\section{BIBLIOGRAFÍA}

\section{Libros}

Ackerman, Bruce, Private Property and the Constitution (Yale University Press, New Haven, London, 1977).

Alessandri, Arturo; Somarriva, Manuel \& Vodanovic, Antonio, Derecho civil. Tratado de los derechos reales. Bienes. Tomo I (Editorial Jurídica de Chile, Santiago, 2014).

Ascarelli, Tullio, Teoría de la concurrencia y de los bienes inmateriales (Studia Albornotiana, 9, Bosch, Barcelona, 1970).

Baylos-Corroza, Hermenegildo, Tratado de derecho industrial (Civitas, Madrid, 2009).

Betegón-Carrillo, Jerónimo; Gascón-Abellán, Marina; Páramo, Juan Ramón de \& Prieto-Sanchís, Luis, Lecciones de teoría del derecho (McGraw-Hill, Madrid, 1997).

Bobbio, Norberto, El problema del positivismo jurídico (Distribuciones Fontamara, México, 2007).

Bugbee, Bruce W., Genesis of American Patent and Copyright Law (Public Affairs Press, Washington, 1967).

Cavalli, Jean, Génesis del Convenio de Berna para la Protección de las Obras Literarias y Artísticas del 9 de septiembre de 1886 (Ministerio del Interior y de Justicia, Dirección Nacional del Derecho de Autor, Telecom, Bogotá, 2006).

Coase, Ronald, The Firm, the Market, and the Law (The University of Chicago Press, Chicago, London, 1990).

Díez-Picazo, Luis \& Gullón-Ballesteros, Antonio, Sistema de derecho civil, volumen III, Tomo 1 (Tecnos, Madrid, 2012).

Duguit, LÉON, Las transformaciones del derecho público y privado (Editorial Heliasta, Buenos Aires, 1975).

Dukeminier, Jesse \& Krier, James, Property (Little, Brown and Company, Boston, 1993).

GonzÁlez-García, José, La facultad de exclusión del propietario (Universidad de Granada, Granada, 1986).

GonzÁlez-JÁcome, Jorge, Los debates del pensamiento jurídico colombiano entre 1886 y 1920 (Pontificia Universidad Javeriana, Bogotá, 2011).

Groethuysen, Bernard, Filosofía de la Revolución Francesa (Fondo de Cultura Económica, FCE, México, 1989).

Grossi, Paolo, La propiedad y las propiedades en el gabinete del historiador (Civitas, Madrid, 2016).

Josipovici, Gabriel, ¿Qué fue de la modernidad? (Turner, Colección Noema, Madrid, 2012).

Josserand, Louis, Derecho civil (Bosch, Buenos Aires, 1950).

Kennedy, Duncan, Tres globalizaciones del derecho y del pensamiento jurídico, 1850- 
2000 (Jorge GonzÁlez-JÁcome, trad., Universidad Externado de Colombia, Bogotá, 2015).

Kohler, Josef, Philosophy of Law (The Boston Book Company, Boston, 1914).

Lacruz-Berdejo, José Luis, Elementos de derecho civil, III, v. 1 (Librería Bosch, Barcelona, 1980).

Lacruz-Berdejo, José Luis, Elementos de derecho civil, III, v. 2 (Librería Bosch, Barcelona, 1980).

Landes, William M. \& Posner, Richard A., The Economic Structure of Intellectual Property Law (Harvard University Press, Cambridge, 2003).

Llamas-Pombo, Eugenio, Orientaciones sobre el concepto y el método del derecho civil (Pontificia Universidad Javeriana, Bogotá, 2009).

Llewellyn, Karl N., The Common Law Tradition: Deciding Appeals (Little, Brown \& Company, Boston, 1960).

Locke, John, Ensayo sobre el gobierno civil (Fondo de Cultura Económica, México, 1941).

Mazeaud, Henri; Mazeaud, Léon \& Mazeaud, Jean, Lecciones de derecho civil (Ediciones Jurídicas Europa-América, Buenos Aires, 1959).

Merges, Robert P., Justifying Intellectual Property (Harvard University Press, Cambridge, 2011).

Mill, John Stuart, Principles of Political Economy (William J. Ashley, ed., Longmans, Green and Co., London, 1965).

Nozick, Robert, Anarchy, State and Utopia (Blackwell Publishing, Malden, Oxford, 1999).

Ostrom, Elinor, Governing the Commons. The Evolution of Institutions for Collective Action (Cambridge University Press, Cambridge, 2015).

Posner, Richard A., El análisis económico del derecho (Fondo de Cultura Económica, México, 1998).

Rodotà, Stefano, El terrible derecho. Estudios sobre la propiedad privada (Civitas, Madrid, 1986).

Rousseau, JeAn-JAcques, El contrato social (Panamericana, Bogotá, 1998).

Sherman, Brad \& Bently, Lionel, The Making of Modern Intellectual Property Law: The British Experience, 1760-1910 (Cambridge University Press, Cambridge, 1999). Disponible en: http://s1.downloadmienphi.net/file/downloadfile4/206/1391108.pdf

Smelser, Neil J. \& Baltes, Paul B., eds., International Encyclopedia of the Social \& Behavioral Sciences (Elsevier, Stanford, California, 2001).

Smith, Henry E., Exclusion and Property Rules in the Law of Nuisance, 90 Virginia Law Review, 4, 965-1049 (2004). Disponible en: http://digitalcommons.law.yale.edu/ cgi/viewcontent.cgi?article $=4054 \&$ context $=$ fss_papers

Waldron, Jeremy, The Right to Private Property (Clarendon Press, Oxford, 1988). 


\section{Contribución en obras colectivas}

Biagioli, Mario, Patent Specification and Political Representation: How Patents Became Rights, en Making and Unmaking Intellectual Property: Creative Production in Legal and Cultural Perspective, 25-40 (Mario Biagioli, Peter Jaszi \& Martha Woodmansee, eds., University of Chicago Press, Chicago, 2011).

Fisher, William W., III, Geistiges Eigentum - ein ausufernder Rechtsbereich: Die Geschichte des Ideenschutzes in den Vereinigten Staaten, en Eigentum im internationalen Vergleich, 265-291 (Hannes Siegrist \& David Sugarman, hg., Vandenhoeck \& Ruprecht, Göttingen, Deutschland, 1999).

Fisher, William W., III, The Growth of Intellectual Property: A History of the Ownership of Ideas in the United States en Eigentum im internationalen Vergleich, 265291 (Hannes Siegrist \& David Sugarman, eds., Vandenhoeck \& Ruprecht, Göttingen, Deutschland, 1999). Disponible en: https://cyber.harvard.edu/people/ tfisher/iphistory.pdf

Grey, Thomas C., The Disintegration of Property, en Property, Nomos XXII, 69-85 (J. Roland Pennock \& John W. Chapman, eds., New York University Press, New York, 1980). Disponible en: https://www.jstor.org/stable/24219422?seq=1\#page_ scan_tab_contents

Sganga, Caterina, EU Copyright Law between Property and Fundamental Rights: A Proposal to Connect the Dots, en Balancing Copyright Law in the Digital Age: Comparative Perspectives, 1-26 (Roberto Caso \& Federica Giovanella, eds., Springer, Berlin, Heidelberg, 2015).

Yu, Peter K., Digital Copyright Enforcement Measures and Their Human Rights Threats, en Research Handbook on Human Rights and Intellectual Property, 455-477 (Christophe Geiger, ed., Edward Elgar Publishing, Cheltenham, Northampton, 2015.

\section{Revistas}

Alchian, Armen A. \& Demsetz, Harold, The Property Right Paradigm, 33 The Journal of Economic History, 1, The Tasks of Economic History, 16-27 (March 1973). Disponible en: http://www.fd.unl.pt/docentes_docs/ma/LTF_MA_24397.pdf

Álvarez-Amézquita, David; Salazar, Óscar Eduardo \& Padilla-Herrera, Julio CÉSAR, Teoría de la propiedad intelectual. Fundamentos en la filosofía, el derecho y la economía, 15 Civilizar, 28, 61-76 (2015). Disponible en: http://revistas. usergioarboleda.edu.co/index.php/ccsh/article/view/280/237

Brennan, Timothy J., Copyright, Property, and the Right to Deny, 68 Chicago-Kent Law Review, 2, 675-714 (1992). Disponible en: http://scholarship.kentlaw.iit.edu/cgi/ viewcontent.cgi?article $=2890 \&$ context $=$ cklawreview

Cohen, Julie E., What Kind of Property is Intellectual Property?, 52 Houston Law Review, 2, 691-707 (2014). Disponible en: http://www.houstonlawreview.org/wp-content/ uploads/2015/01/8-Cohen.pdf

Dyzenhaus, David, The Genealogy of Legal Positivism, 24 Oxford Journal of Legal 
Studies, 1, 39-67 (2004).

Fisher, William W., III, When Should We Permit Differential Pricing of Information?, 55 UCLA Law Review, 1, 1-38 (2007). Disponible en: https://www.uclalawreview. org/pdf/55-1-1.pdf

Hovenkamp, Herbert J., The Emergence of Classical American Patent Law, 58 Arizona Law Review, 263-306 (2016). Disponible en: https://papers.ssrn.com/sol3/papers. cfm?abstract_id=2625596, http://scholarship.law.upenn.edu/cgi/viewcontent.cgi ?article $=2801 \&$ context $=$ faculty_scholarship

Hughes, Justin, Copyright and Incomplete Historiographies: of Piracy, Propertization, and Thomas Jefferson, 79 Southern California Law Review, 993-1084 (2006). Disponible en: https://papers.ssrn.com/sol3/papers.cfm?abstract_id=934869

Hughes, Justin, The Philosophy of Intellectual Property, 77 The Georgetown Law Journal, 2, 287-366 (1988). Texto disponible en: https://pdfs.semanticscholar.org/3932/ bdda601812eb6212725f38285e72dc8fc70b.pdf

Kelley, Patrick J., Holmes, Langdell and Formalism, 15 Ratio Juris, 1, 26-51 (2002).

Kinsella, N. Stephan, Against Intellectual Property, 15 Journal of Libertarian Studies, 2, 7-70 (2001). Disponible en: https://mises.org/library/against-intellectualproperty-2

Kovacic, William E. \& Reindl, Andreas P., An Interdisciplinary Approach to Improving Competition Policy and Intellectual Property Policy, 28 Fordham International Law Journal, 4, 1062-1090 (2004). Disponible en: http://ir.lawnet.fordham.edu/ cgi/viewcontent.cgi?article $=1980 \&$ context $=\mathrm{ilj}$, http://ir.lawnet.fordham.edu/ilj/ vol28/iss $4 / 7$

Lemley, Mark A., Ex Ante versus Ex Post Justifications for Intellectual Property (February 2, 2011), 71 University Chicago Law Review, 129-149 (2004); UC Berkeley Public Law Research Paper No. 144. Disponible en: https://papers. ssrn.com/sol3/papers.cfm?abstract_id=494424

Lemley, Mark A., The Economics of Improvement in Intellectual Property Law (September 1, 2008), 75 Texas Law Review, 989-1084 (1997); Stanford Law and Economics Olin Working Paper No. 365. Disponible en: https://papers.ssrn.com/ sol3/papers.cfm?abstract_id=1274199

Marcone, Julieta, Hobbes: entre el iusnaturalismo y el iuspositivismo, 1 Andamios, Revista de Investigación Social, 2, 123-148 (2005). Disponible en: http://www. redalyc.org/articulo.oa? $\mathrm{id}=62810206$

Maughan, Charles William, Property and Intellectual Property: Foundations in Law and Economics, 22 Prometheus, Critical Studies in Innovation, 4, 379-391 (December, 2004).

Merrill, Thomas W. \& Smith, Henry E., Making Coasean Property More Coasean (February 9, 2011), 54 Journal of Law and Economics, 4, S77-S104 (2011); Harvard Law and Economics Discussion Paper No. 688; Columbia Public Law Research Paper No. 11-262. Disponible en: https://papers.ssrn.com/sol3/papers. cfm?abstract_id $=1758846$

Moore, Adam Daniel, A Lockean Theory of Intellectual Property, 21 The Hamline Law Review, 65-108 (1998). Disponible en: https://papers.ssrn.com/sol3/papers. 
cfm?abstract_id=1980882

Mossoff, Adam, Exclusion and Exclusive Use in Patent Law, 22 Harvard Journal of Law \& Technology, 2, 321-379 (2009). Disponible en: http://jolt.law.harvard.edu/ articles/pdf/v22/22HarvJLTech321.pdf

Mossoff, Adam, Rethinking the Development of Patents: An Intellectual History, 15501800, 52 Hastings Law Journal, 1255-1322 (2001). Disponible en: https://papers. ssrn.com/sol3/papers.cfm?abstract_id=863925

Mossoff, Adam, What is Property? Putting the Pieces Back Together, 45 Arizona Law Review, 371-443 (2003). Disponible en: https://papers.ssrn.com/sol3/papers. cfm?abstract_id $=438780$

Mossoff, Adam, Who Cares What Thomas Jefferson Thought About Patents? Reevaluating the Patent "Privilege" in Historical Context, 92 Cornell Law Review, 5, 953-1012 (2007); MSU Legal Studies Research Paper No. 03-21. Disponible en: http:// scholarship.law.cornell.edu/cgi/viewcontent.cgi?article $=3067 \&$ context $=\mathrm{clr}$

Penner, James E., The "Bundle of Rights” Picture of Property, 43 UCLA Law Review, 3, 711-820 (1996).

Raustiala, Kal \& Sprigman, Christopher Jon, The Piracy Paradox Revisited, 61 Stanford Law Review, 5, 1201-1225 (2009). Disponible en: https://papers.ssrn.com/sol3/ papers.cfm?abstract_id $=1404247$

Rodríguez-Paniagua, José María, El formalismo ético de Kant y el positivismo jurídico, 9 Anuario de Filosofía del Derecho, 35-50 (1962). Disponible en: https://dialnet. unirioja.es/servlet/articulo?codigo $=2060145$

Santaella-Quintero, Héctor, Notas sobre el concepto y la garantía de la propiedad privada en la Constitución colombiana, 21 Revista de Derecho Privado, 233-253 (julio-diciembre de 2011). Disponible en: http://revistas.uexternado.edu.co/index. php/derpri/article/view/2989/2633

Seckelmann, Margrit, From the Paris Convention (1883) to TRIPS Agreement (1994): the History of the International Patent Agreements as a History of Propertisation?, 14 Jahrbuch der Juristischen Zeitgeschichte, 1, 46-63 (2013).

Smith, Henry E., Property and Property Rules, 79 New York University Law Review, 17191798 (2004). Disponible en: http://digitalcommons.law.yale.edu/cgi/viewcontent. cgi?article $=4053 \&$ context $=$ fss_papers

Weinrib, ERnest J., Legal Formalism: On the Immanent Rationality of Law, 97 The Yale Law Journal, 6, 949-1016 (1988).

Wright, Michael T., Epicyclic Gearing and the Antikythera Mechanism, Part II, 29 Antiquarian Horology, 1, 51-63 (2005).

\section{Working paper}

Katz, Larissa M., Exclusion and Exclusivity in Property Law (Legal Studies Research Paper Series No. 08-02, April 1, 2008). Disponible en: https://papers.ssrn.com/ sol3/papers.cfm?abstract_id=1126674

Priel, Dan, Towards Classical Legal Positivism (Osgoode CLPE Research Paper No. 
20, 2011). Disponible en: https://papers.ssrn.com/sol3/papers.cfm?abstract_ $\mathrm{id}=1886517$

\section{Conferencias, documentos, informes, reportes, tesis}

Foucault, Michel, La verdad y las formas jurídicas (Conferencias dictadas en la Pontifícia Universidade Católica do Rio de Janeiro, 1973). Disponible en: http:// www.fmmeducacion.com.ar/Bibliotecadigital/Foucault_Laverdad.pdf

Pérez-Lledó, JuAn A. \& GonzÁlez-Lagier, Daniel, Apuntes sobre la filosofía del derecho de los siglos XIX y XX: de la Escuela de la Exégesis a Ronald Dworkin (2012). Disponible en: http://rua.ua.es/dspace/handle/10045/20557

\section{Tratados internacionales}

Organización Mundial de Propiedad Intelectual, OMPI, Convenio que establece la Organización Mundial de la Propiedad Intelectual, Estocolmo, 14 de julio de 1967, enmendado el 28 de septiembre de 1979. Disponible en: http://www.wipo. int/treaties/es/convention/

Unión para la Protección de los Derechos de los Autores sobre sus Obras Literarias y Artísticas, Convenio de Berna para la protección de las obras literarias y artísticas, 9 de septiembre de 1886. Disponible en: http://www.wipo.int/treaties/ es/text.jsp?file_id=283698

\section{Normas, conceptos y documentos oficiales internacionales}

Comisión Europea, Directrices sobre la aplicabilidad del artículo 101 del Tratado de Funcionamiento de la Unión Europea a los acuerdos de cooperación horizontal, 2011/C 11/01, Diario Oficial de la Unión Europea, 14 de enero de 2011. Disponible en: http://eur-lex.europa.eu/legal-content/ES/TXT/?uri=celex:52011XC0114(04)

España, Ley sobre Hipoteca Mobiliaria y Prenda sin Desplazamiento de la Posesión en España, de 16 de diciembre de 1954, 352 Boletín Oficial del Estado, BOE, 18 de diciembre de 1954. Disponible en: https://www.boe.es/buscar/act. php?id=BOE-A-1954-15448

Estados Unidos, Federal Trade Commission, FTC, To Promote Innovation: The Proper Balance of Competition and Patent Law and Policy (October 2003). Disponible en: https://www.ftc.gov/sites/default/files/documents/reports/ promote-innovation-proper-balance-competition-and-patent-law-and-policy/ innovationrpt.pdf

Francia, Código Civil de 1804. Disponible en: http://gallica.bnf.fr/ark:/12148/ bpt6k1061517

Reino Unido, Estatuto de la Reina Ana, An act for the encouragement of learning, by vesting the copies of printed books in the authors or purchasers of such copies, 
during the times therein mentioned, 10 de abril de 1710. Disponible en: https:// www.copyrighthistory.com/anne.html

\section{Normas, conceptos y documentos oficiales colombianos}

Colombia, Consejo Nacional de Política Económica y Social, CONPES, Documento CONPES 3533, Bases de un plan de acción para la adecuación del sistema de propiedad intelectual a la competitividad y productividad nacional, 2008-2010 (14 de julio de 2008). Disponible en: http://www.disanejercito.mil.co/index. php?idcategoria $=144363$

Colombia, Ley 1676 de 2013, por la cual se promueve el acceso al crédito y se dictan normas sobre garantías mobiliarias, 48.888 Diario Oficial, 20 de agosto de 2013. Disponible en: http://www.secretariasenado.gov.co/senado/basedoc/ ley_1676_2013.html

\section{Jurisprudencia internacional}

Estados Unidos, Corte Suprema de Justicia, Festo Corp. v. Shoketsu Kinzoku Kogyo Kabushiki Co., 535 US 722, 730 (May 28, 2002). Disponible en: https://supreme. justia.com/cases/federal/us/535/722/

Estados Unidos, Corte Suprema de Justicia, Florida Prepaid Postsecondary Education Expense Boardv. College Savings Bank et al., Certiorari to the United States Court of Appeals for the Federal Circuit, 527 US 627, 642 (June 23, 1999). Disponible en: https://supreme.justia.com/cases/federal/us/527/627/case.html

Unión Europea, Tribunal de Justicia, Gran Sala, Johan Deckmyn y Vrijheidsfonds $V Z W$ contra Helena Vandersteen y otros, Sentencia de 3 de septiembre de 2014, Asunto C-201/13. Disponible en: http://curia.europa.eu/juris/liste. jsf?language $=$ es \&num $=\mathrm{C}-201 / 13$

Reino Unido, Corte del Rey, Millar v. Taylor (1769) 98 ER 233.

\section{Jurisprudencia colombiana}

Colombia, Corte Constitucional, Sentencia C-006-93, 18 de enero de 1993, magistrado ponente Eduardo Cifuentes-Muñoz. Disponible en: http://www. corteconstitucional.gov.co/relatoria/1993/C-006-93.htm

Colombia, Corte Constitucional, Sentencia C-334-93, 12 de agosto de 1993, magistrado ponente Alejandro Martínez-Caballero. Disponible en: http://www. corteconstitucional.gov.co/relatoria/1993/c-334-93.htm

Colombia, Corte Constitucional, Sentencia C-595-99, 18 de agosto de 1999, magistrado ponente Carlos Gaviria-Díaz. Disponible en: http://www.corteconstitucional. gov.co/relatoria/1999/c-595-99.htm

Colombia, Corte Constitucional, Sentencia C-148-15, 7 de abril de 2015, magistrada ponente Gloria Stella Ortiz-Delgado. Disponible en: http://www. corteconstitucional.gov.co/relatoria/2015/c-148-15.htm 